\title{
On the Arbitrariness and Robustness of Multi-Dimensional Poverty Rankings
}

\author{
Mozaffar Qizilbash *
}

June 2004

\begin{abstract}
It is often argued that multi-dimensional measures of well-being and poverty-such as those based on the capability approach and related views - are ad hoc. Rankings based on them are not, for this reason, robust to changes in the selection of weights used. In this paper, it is argued that the extent of potential arbitrariness and the range of issues relating to robustness have been underestimated in this context. Several issues relating to both the identification of the poor and the use of dimension-specific data are distinguished. These issues are then discussed in the context of the inter-provincial ranking of poverty in South Africa in 1995-6. It turns out that this ranking is fairly robust, and that some important policy-relevant results about the distinction between 'income'/'expenditure' and 'human' poverty for the South African context are reinforced rather than undermined by checking for robustness. In particular, while KwaZulu Natal is in the best three in terms of the standard expenditure measures for various choices of poverty line, it is third worst in terms of all the multi-dimensional rankings presented here.
\end{abstract}

Keywords: Human Poverty Index, Borda ranking, South Africa

JEL classification: D60, I31, I32

Copyright (C) Author(s) 2004

* School of Economic and Social Studies, UEA, Norwich, UK; e-mail: m.qizilbash@uea.ac.uk

This is a revised version of the paper originally prepared for the UNU-WIDER Conference on Inequality, Poverty and Human Well-Being, 30-31 May 2003, Helsinki.

UNU-WIDER acknowledges the financial contributions to the research programme by the governments of Denmark (Royal Ministry of Foreign Affairs), Finland (Ministry for Foreign Affairs), Norway (Royal Ministry of Foreign Affairs), Sweden (Swedish International Development Cooperation Agency-Sida) and the United Kingdom (Department for International Development). 


\section{Acknowledgements}

Earlier versions of this paper were presented at the Third Conference on the Capability Approach, From Sustainable Development to Sustainable Freedom, University of Pavia, September 2003 and at the conference on Inequality, Poverty and Human Well-Being, UNU-WIDER, Helsinki, May 2003. I am very grateful to Tania Burchardt, David Clark, Sakiko Fukuda-Parr, Des Gasper, Stephan Klasen, Esfandiar Maasoumi, Subbu Subramanian and others for comments on those versions. Any errors or omissions are mine.

The World Institute for Development Economics Research (WIDER) was established by the United Nations University (UNU) as its first research and training centre and started work in Helsinki, Finland in 1985. The Institute undertakes applied research and policy analysis on structural changes affecting the developing and transitional economies, provides a forum for the advocacy of policies leading to robust, equitable and environmentally sustainable growth, and promotes capacity strengthening and training in the field of economic and social policy making. Work is carried out by staff researchers and visiting scholars in Helsinki and through networks of collaborating scholars and institutions around the world.

www.wider.unu.edu

publications@wider.unu.edu

UNU World Institute for Development Economics Research (UNU-WIDER)

Katajanokanlaituri 6 B, 00160 Helsinki, Finland

Camera-ready typescript prepared by Adam Swallow at UNU-WIDER

Printed at UNU-WIDER, Helsinki

The views expressed in this publication are those of the author(s). Publication does not imply endorsement by the Institute or the United Nations University, nor by the programme/project sponsors, of any of the views expressed. 


\section{Introduction}

There is now a considerable and growing literature on multi-dimensional measures of poverty and well-being. The literature is both theoretical and empirical, and some of it is policy-oriented. The policy relevance of multi-dimensionality relates, in part, to the genuine possibility that an uni-dimensional approach to the measurement of well-being and poverty - such as that involved in some of the income- or expenditure-focussed poverty literature - is likely to underestimate the 'richness' or complexity of the nature of poverty, which needs to be addressed in any policy for poverty eradication. Furthermore, use of a multi-dimensional framework might actually alter the particular set of people who are identified as poor.

One response to arguments in favour of multi-dimensional approaches - such as Amartya Sen's capability approach and related views of well-being - claims that, while multi-dimensional measures can be useful, they are usually ad hoc. Multi-dimensional measures typically involve some sort of weighting scheme or exercise to capture the relative importance of the different dimensions of poverty. Any ranking of countries or provinces which is based on such measures must then be highly sensitive to the specific weighting scheme adopted. There are various ways of responding to this challenge. Nonetheless, this issue is also relevant in the context of some uni-dimensional measures - such as those income- or expenditure-based metrics which use a basket of commodities, or a set of 'basic needs', to establish the income or expenditure poverty line. It is argued, in this paper, that there are numerous issues aside from than the specific issue of weighting which are relevant to the robustness of rankings based on these measures. In particular, there are issues relating to the choice of dimensions which are relevant, and to the choice of the 'bottom line' in terms of each dimension, in the analysis of poverty. These need to be distinguished from issues relating to the weighting of dimensions if robustness is to be seriously examined in the multi-dimensional context.

In this paper, I address some of the relevant issues in relation to two standard approaches to multi-dimensional poverty ranking - the Borda score and the Human Poverty Index (HPI) developed by the United Nations Development Programme (UNDP) - using data from the 1996 South African Census. The Census data have been the focus of much of the recent literature on South Africa. Some of this literature has focussed on the inter-provincial picture of poverty and the distribution of poverty eradication grants to the various provinces. This paper focusses on inter-provincial rankings and it is clearly relevant to debates in this literature. In particular, it is concerned with whether some findings about the contrast between the picture of poverty which emerges from the income- or expenditure-based and multi-dimensional measures is robust.

The paper is organised as follows: in section 1, the various distinct issues raised by multi-dimensionality are discussed; in section 2, the HPI and the Borda score are introduced; arbitrariness and robustness with respect to the choice of dimensions and weighting are examined in the South African context in section 3; in section 4, issues relating to the choice of the 'bottom line' in each dimension are discussed; in section 5 , the analysis is related to policy issues; and section 6 concludes. 


\section{Issues raised by the multi-dimensionality of poverty and well-being}

There are numerous distinct issues relating to arbitrariness and robustness which are raised in the context of multi-dimensional measures of well-being and poverty. One can distinguish between issues which are: (i) dimension specific; and (ii) those which relate to the variety of dimensions. Many issues which are dimension specific - such as how to define a 'bottom line' in some dimension of poverty-are closely related to those which arise in the income- or expenditure-based uni-dimensional context. Nevertheless, problems which arise because of the variety of dimensions involve formal and substantive issues which - while they may have been discussed in the context of income or expenditure poverty - often need to be dealt with in a more explicit manner in the multi-dimensional context.

To see how these problems arise it is worth considering the context in which multidimensional measures are being used. One central issue involved in poverty analysis is the identification of the poor. I term problems which relate primarily to this issue 'identification problems'. Given the multi-dimensionality of poverty, numerous issues relating to both (i) and (ii) arise in relation to such problems. First, in relation to (ii), there is the choice of dimensions of well-being which are relevant to poverty analysis. Once this choice has been made, there is the further dimension specific issue of how much a person has to fall short to be poor in terms of each dimension. This is the issue of the 'critical level' below (or at) which a person is defined as poor in some dimension. In both cases, furthermore, it can be argued that there may be imprecision or 'fuzziness'. Such vagueness or fuzziness about the 'bottom line' in each dimensionsometimes called 'vertical vagueness' - is distinct from vagueness about the dimensions of well-being which are relevant to the poverty evaluation exercise-'horizontal vagueness' (Qizilbash, 2003). When researchers attempt to address these two forms of vagueness there is a further possibility of arbitrariness. In most exercises, where vertical vagueness is allowed for, there is some level of well-being above which a person is definitely not poor, and another below which she is definitely poor. It can be argued that the way in which these levels are fixed is arbitrary. Issues relating to this potential arbitrariness have been raised and discussed in the fuzzy set theoretic poverty literature (Cerioli and Zani, 1990; Cheli and Lemmi, 1995; Chiappero Martinetti, 1994, 1997, 2000; Lelli, 2001).

Even if we put issues relating to any specific dimension to one side, there is also the issue of how to define or identify someone as poor, taking account of all the different dimensions of poverty and the various critical levels which have been selected. There are numerous approaches to dealing with this identification problem. Some take it that some individual (or household) is poor if she (or it) is poor in any dimension relating to poverty (Bourguignon and Chakravarty, 2003; Brandolini and d'Alessio, 2001 inter alia). ${ }^{1}$ An alternative solution to this problem would identify an individual (or household) as poor if she (or it) is poor in terms of all the specified dimensions. Yet another possibility is to classify people (households) as poor if they are poor in terms of some overall index or average of indices relating to poverty (e.g. Klasen, 1997, 2000). In this last case, a further 'bottom line' is usually specified in terms of the average, or

1 Clark and Qizilbash (2002) use a similar methodology, except that they allow a person (household) to be 'core poor' if she (it) is poor on a 'core dimension', a dimension which is part of any way of specifying the notion of poverty. This methodology allows for horizontal vagueness. 
relevant overall index used. In Stephan Klasen's application of the capability approach - which sees poverty in terms of an inability to achieve certain crucially important functionings, or 'basic capability failure' (Sen, 1993 and 1999) - to the South African context (Klasen, 2000), two such 'bottom lines' are specified. One uses the bottom quintile in terms of his deprivation measure-which involves an unweighted average of various indices - while the other uses the bottom 40 per cent in terms of that measure. In Klasen's application there is also the standard problem of the choice of weights which are assigned to specific dimensions if an overall index or average is used. However, this problem is quite distinct from both those involved in: defining the bottom line in terms of each dimension and; defining the bottom line in terms of the average of indices (weighted or non-weighted).

Finally, there is the relative importance of the range, or number, of dimensions in which some person or group is poor, and of the extent of deprivation in some specific dimension. This contrast is sometimes characterised in terms of the 'width' and the 'depth' of poverty (see Anand and Sen's note in UNDP, 1997). The relative importance to be given to width and depth is also, in effect, a weighting problem, but it is distinct from the weighting of different dimensions. Each of these issues must be dealt with at a different level in multi-dimensional approaches. There is the possibility of arbitrariness at each level.

A growing literature which looks at the properties of multi-dimensional measures and rankings has begun to take on some of these issues explicitly (Tsui, 1997; Bourguignon and Chakravarty, 2002, 2003; Atkinson, 2003 inter alia). ${ }^{2}$ However, in most applications of multi-dimensional measures to identification problems only some of these issues are usually explicitly raised and addressed. So while most of the issues which are relevant to identification and weighting are clearly distinguished by Bourguignon and Chakravarty (2003), the issue of vagueness is not discussed. Furthermore, it is only rarely the case that theoretical arguments are presented in favour of the actual approach that is taken in response to issues raised by identification problems in the multi-dimensional context. So, for example, Klasen uses an average of deprivation indices in dealing with the identification problem without much justification for the use of an averaging approach. ${ }^{3}$

There is also the issue of the selection of dimensions actually used. In most applications of the capability or basic needs frameworks, some fairly uncontroversial dimensions of well-being are used. So, for example, in his application of the capability approach, Klasen invokes some fairly uncontroversial aspects of the quality of life, such as health, education etc. and he refers to Sen's work in justifying the selection used in his 'core deprivation index'. Sometimes data on people's perceptions or evaluations are used to justify the choice of dimensions selected in applying the particular approach (Klasen, 2000; Clark and Qizilbash, 2002). In the absence of such data, it is often not clear whether, or how, the approach taken to the choice of dimensions can be justified. It is

2 There is a related literature about the measurement of multidimensional inequality which includes Maasoumi (1986) and Atkinson and Bourguignon (1987).

3 Klasen does, nonetheless, test for sensitivity of the weighting scheme adopted and argues that his results - which focus on an unweighted average of indices - are robust to the choice of an alternative averaging scheme, which uses principal-component analysis. So Klasen does test for robustness at that level. 
certainly plausible to claim, in many cases, that the approach actually taken is ad hoc. In fact, often the best defence of the actual indicators selected relates purely to the limits of data availability.

While issues relating to identification problems are perhaps the most challenging that are raised by the literature on multi-dimensional poverty measurement, there are many contexts in which researchers, or policy makers, are not trying, specifically, to identify the poor using a multi-dimensional approach. Problems of the sort just discussed can, nonetheless, arise in the context of national or provincial data which relate to how deprived people or households are in terms of particular dimensions. It is one such context of application - involving inter-provincial rankings - that I shall be concerned with in much of this paper. In this context, some group - such as those who are illiterate-has usually already been identified as deprived or poor in the specific dimension - such as education or knowledge-involved. Indeed, in this context, often the only published data which is available is dimension-specific. ${ }^{4}$ The central issue is about how to arrive at a more general judgement or measure of poverty on the basis of such data. It is this problem which is involved in constructing some multi-dimensional poverty measures - such as the HPI developed by Sudhir Anand and Amartya Sen for the UNDP. In this case too, issues about the choice of dimensions and the weights given to the selected dimensions, as well as issues relating to 'width' and 'depth', and to horizontal and vertical vagueness, are relevant. So the broad range of issues is similar in the context of both identification problems and measures which use dimension specific information.

Related issues have arisen in the context of income and expenditure measures. So, for example, there has been the issue of whether to focus on just one dimensionnutrition - or some basket of 'basic needs' when estimating income and expenditure poverty lines. There have also been issues about weights as well as about uncertainty about the precise location of the 'true poverty line' (Ravallion, 1994). Given a general concern with such issues, a sophisticated literature has grown which allows for many different income poverty lines (Atkinson, 1987; Foster and Shorrocks, 1988; Ravallion, 1994). However, given the focus on one dimension, most of the discussion surrounds the question of which poverty line - or which range of poverty lines - to choose in evaluation. This issue is sometimes related to the question of whether to pick an 'absolute' or a 'relative' poverty line. It is complicated by further issues about the unit of accounting (i.e. individual or household) and possible adjustments of the data to convert members of households into 'equivalent adults' when household data are being used to generate indices of individual poverty. Some of the recent literature on multidimensional poverty measures and rankings (notably Bourguignon and Chakravarty, 2002, 2003; Atkinson, 2003) attempts to extend the earlier formal analysis of income (or expenditure) poverty to the multi-dimensional case.

Given the problems posed by arbitrariness, as well as issues relating to weighing, one approach to addressing these issues has been to rely only on judgements which are

4 Dutta, Pattanaik and Xu (2003) discuss the relation between measures which use, and combine, dimension specific 'aggregate' data and measures which begin with observations on individuals and households and aggregate that information. They argue that measures which begin with aggregate data will very rarely lead to the same picture of poverty as those which begin with individual or household data. 
invariant to all the possible choices of critical levels, dimensions or weights etc. used. This is the 'intersection' or 'dominance' approach-associated with Amartya Sen (1992: 47-9)—which has been very influential. While it has had considerable influence on the academic literature, this approach has had less of an impact on the policy debate where specific weights and poverty lines are generally used.

\section{The Human Poverty Index and the Borda ranking}

In the policy context, Sen himself has been very active in developing new measures which are related to people's 'capabilities to live valuable lives' using direct indices relating to the quality of life. The UNDP's measures of human development and human poverty are examples of these measures. These measures involve very specific weights and component indices, which are potentially contentious. While certain attempts have been made to offer a qualified defence of the actual weights used in, and the dimensions selected for, these measures (Haq, 1995; Anand and Sen, 2000 inter alia) issues about arbitrariness and robustness remain.

To investigate these issues, I focus here on the UNDP's HPI and one alternative method of ranking - the Borda score ranking method. There are actually two variants of the HPI, one for developing countries and one for industrialised countries. The HPI for developing countries-HPI-1 - involves component indices relating to three dimensions which are thought of as related to 'basic capabilities' - health, education and a 'decent standard of living'. Importantly, it exclusively involves direct measures of the quality of life relating to various dimensions and is, for this reason, labelled an index of 'human poverty' rather than 'income poverty'. Each component index used in the HPI-1 is either a headcount index or an average of headcount indices. The component indices are: the probability of not surviving till the age of 40 (for health); the adult illiteracy rate (for education); and a composite of the proportion of the population not using improved water sources and the proportion of underweight children under the age of 5 (for 'a decent standard of living').

The HPI-1 is actually a special case of a family of measures. I shall call this family the 'Anand-Sen family of measures', since it is based on the work of Sudhir Anand and Amartya Sen (UNDP, 1997). In defining this family of measures each component index used is termed a 'shortfall' and each shortfall is indexed $i$ so that $S_{i}$ is the shortfall in terms of component $i$, for $n$ dimensions, so that $i=1,2 \ldots n$, and the weights attached to these components are written $w_{i}$. The Anand-Sen family of measures is a weighted average of power $\alpha$ of these shortfalls. It is written $S(\alpha)$, where:

$$
S(\alpha)=\left\{\left(\sum_{i=1}^{n} w_{i} S_{i}^{\alpha}\right) /\left(\sum_{i=1}^{n} w_{i}\right)\right\}^{1 / \alpha}
$$

In the case of the UNDP's HPI-1, $n$ is three, equal weights are used and weights sum to one-so that each dimension is given a weight of $1 / 3$ - and $\alpha$ is set above 1 . The motivation for setting $\alpha$ above one is to allow for the 'depth' of a shortfall in terms of each component index to be picked up. An increase in a component index at a higher level of deprivation in terms of that index will register more than at a lower level with $\alpha>1 . \alpha$ is actually set at 3 for HPI-1. If it had been set at $1,(1)$ would reduce to an arithmetic average. There are numerous issues relating to arbitrariness and robustness 
that are relevant to rankings based on the HPI-1. First, there is the issue of robustness to alternative choices of the set of dimensions of poverty, given horizontal vagueness about what counts as a 'basic capability' (or 'basic need') as opposed to a 'non-basic capability' (or 'non-basic need'). Second, there is the question of whether rankings based on this index might change if we adjust the weights given to each dimension. Third, there is the issue of the sensitivity of rankings to the weight given to 'depth' i.e. the choice of $\alpha$. Finally, there is the issue of the cut-offs which are used in each dimension (such as the choice of 40 years in the case of the health component, and the choices of cut-offs for defining people as undernourished and illiterate). In this context, 'vertical vagueness' would be relevant.

One worry which is sometimes expressed about measures like the Anand-Sen family of measures is that they involve 'cardinal information'-information (in the poverty context) about levels of shortfall in each dimension of poverty. ${ }^{5}$ If there are consistent biases in the data, such measures might be misleading (Dasgupta, 1993: 109). So there is a case for looking at whether rankings based on the HPI remain unaffected when some method of ranking which does not use cardinal information is used. One popular alternative approach is the rank order method developed by the French mathematician Jean-Charles de Borda. This approach involves simply assigning a rank order score to each group (province, nation etc.) being compared in terms of each component index. Adding up the rank order scores gives the 'Borda score'. Ranking groups according to this score gives the 'Borda ranking'. Unlike the Anand-Sen family of measures, this method relies exclusively on 'ordinal information'-because it uses rank order scoresso that changes in levels of poverty in specific dimensions have no impact on the Borda score if they leave rank orders in specific dimensions unchanged. Clearly there are weighting issues relating to, and criticisms of, the Borda ranking (Qizilbash, 1997). However, the use of the Borda ranking in this paper is limited. It serves as an alternative method which can be compared to the ranking which emerges from the Anand-Sen family of measures.

\section{Inter-provincial comparisons in South Africa: dimensions and weights}

In addressing issues relating to arbitrariness and robustness, I focus on of the interprovincial ranking as regards poverty in South Africa in 1995-6. In this context, it is not obvious that the component indices used in the UNDP's HPI-1 are actually appropriate. The HPI-1 is used primarily for the purpose of international rankings of poverty, and nation specific priorities or issues may not be relevant for such rankings. In the South African context (as in many others), there is a strong case for the inclusion of data relating to unemployment, which does not feature in the UNDP's HPI-1. ${ }^{6}$ The indices which I focus on here are ones which are listed in the publications which emerged from the 1996 South African Census. They relate to some of the standard dimensions invoked in multi-dimensional poverty measures. However, the use of some of these indices can also be justified on the grounds that they relate to dimensions which are either

5 Of course, there are other potential problems with such measures. Majumdar and Subramanian (2001) develop a measure which adjusts for inequality and apply their approach in the context of the interprovincial picture of poverty in India.

6 It is included in the UNDP's HPI-2 for industrialised countries. 
prioritized, or identified as, components of a minimally adequate life by South Africans themselves (Klasen, 2000; Clark, 2002; Clark and Qizilbash, 2002). Related indices are used in Stephan Klasen's attempt to apply the capability approach to the South African context. Once we have an initial selection of indices and dimensions, issues of robustness can be addressed.

The initial set of selected dimensions which relate to the quality of life is: employment; health; access to clean water; shelter; knowledge; energy use; and participation in the life of the community. Some of these (such as knowledge) relate primarily to what are thought of as the constitutive elements of well-being, while others (such as energy use) relate mostly to the requirements of a good life. ${ }^{7}$ As regards the 'bottom line' in terms of these dimensions, I shall make fairly arbitrary judgements in this section, and allow for different bottom lines in section 4. Specific indices need to be selected to proxy for these dimensions. In each case the chosen index is an imperfect proxy for the relevant dimension. So in the case of employment, the relevant index used is the rate of unemployment. In the case of water access, it is the proportion of the households whose access to water is from a dam, river, stream or spring. In the case of knowledge, the component index is the proportion of individuals above twenty years of age with no schooling at all. In the case of health, there was no useful index in the Census publications, and an index relating to sanitation is used. This relates to the nature of a household's refuse removal, or lack of such removal. The index used is the proportion of households without any refuse removal at all. In the case of shelter, the relevant index was the proportion of households living in traditional dwellings, informal housing (shacks etc.), caravans and tents, as well as the homeless. An indicator relating to the energy used for cooking is also included: the proportion of households that use wood for cooking. Finally, one further index relating to engagement in social existence-and, in particular, the ability to communicate - is included: the proportion of households with no access to a telephone. This indicator might be justified in terms of considerations relating to 'social exclusion'. It is related to, and a proxy for, the inability to participate in the life of the community. Of course, some might doubt that this indicator relates to 'basic capabilities' at all. Our intuitions about it might well be 'fuzzy', so that there is 'horizontal vagueness' about whether it really is 'basic' or not.

In Table 1, values for these indices are presented for each of the South African provinces as well as for the whole of South Africa. Before embarking on the specific ranking exercises, it is worth mentioning some claims in the related literature. In particular, Klasen (2000) has argued-using data for 1993-that there were more households living in capability poverty in KwaZulu Natal, than would emerge from an examination of income or expenditures alone. Qizilbash (2002) echoes this result using dimension specific data from the 1996 Census publications on the basis of an interprovincial ranking using Borda's method: the multi-dimensional ranking based on a selection of direct indices gives a quite different ordering of the provinces as compared to the standard expenditure measure quoted in the Census publications. In particular, KwaZulu Natal is amongst the worst three, while the Free State is amongst the three best in terms of the human poverty ranking. This result suggests a quite different ranking of the South African states as regards 'human poverty' to that based on

7 This is not to say that any one of the dimensions relates exclusively to ends which are constitutive of a good life or means to achieving that life. Knowledge can, for example, be both a means an end. 
'expenditure poverty', since the Free State is usually amongst the worst provinces in terms of expenditure poverty measures, even when such expenditures are adjusted for household size (Leibbrandt and Woolard, 2000; Ngwane et al. 2001). ${ }^{8}$ Nonetheless, the relative position of the Free State and KwaZulu Natal tends to depend on the specific poverty line selected (Leibbrandt and Woolard, 2000: 48) when using 1993 data. However, using data from 1995 and the Foster, Greer and Thorbecke class of poverty indices, Murray Leibbrandt and Ingrid Woolard conclude that 'KwaZulu Natal has the third lowest incidence of poverty' (Leibbrandt and Woolard, 2000: 52) — with only the Western Cape and Gauteng having a lower incidence-and that this result does not depend on the specific poverty line used. So one must conclude that in 1995 expenditure poverty was higher in the Free State than in KwaZulu Natal, and that this result is robust. This conclusion also emerges from the 1996 Census publications (such as Statistics South Africa, 2000). Qizilbash's result thus suggests that the expenditure and human poverty pictures are quite different. However, this result emerges from a specific choice of non-income indices and one particular method of ranking - the Borda score. How robust is this result about the relative position of the Free State and KwaZulu Natal in human and expenditure poverty rankings?

In Table 2, the Anand-Sen family of measures is given for values of $\alpha$ equal to one, two and three. As with the HPI-1, equal weights are used, and set at $1 / n$. In the case where $\alpha=1$, we simply have an arithmetic average of the indices; in the case where $\alpha=3$, we have a local variant of the HPI-1. In the case where $\alpha=2$, 'depth' is given more importance than in the arithmetic average, but less importance than in the variant of the HPI-1. The measures are calculated both for the full list of seven indices as well as for as a subset of five indices - relating exclusively to education, employment, access to clean water, rubbish disposal and shelter. In the shorter list, the indices relating to telephone access and energy use have been removed to allow for possible issues relating to horizontal vagueness, and to check for sensitivity to the choice of dimensions. The remaining indices relate to what may be considered to be the less controversial dimensions: health, employment, clean water, education and shelter. It is noticeable that KwaZulu Natal does worse than the Free State in terms of the Anand-Sen family of measures, for all values of $\alpha$, and both selections of dimensions. This is not surprising because it does worse in terms of each of the component indices used. An elementary implication of this fact is that KwaZulu Natal must do worse than the Free State whatever the weights assigned to the different dimensions. In this case, then, Sen's 'intersection' approach is useful and we have a robust ranking of the provinces which reinforces results in the existing literature. The contrast between the human and expenditure poverty performances of KwaZulu Natal and the Free State seems, thus, to be robust to the selection of dimensions and to the choice of weights.

8 KwaZulu Natal, nonetheless, has one of the highest shares of expenditure poverty, given its population size. 
Table 1. Headcount Indices of Poverty in Various Dimensions in South Africa 1996

\begin{tabular}{|c|c|c|c|c|c|c|c|c|c|c|}
\hline Indicator & E Cape & Free State & Gauteng & KwaZulu Natal & Mpumalanga & N Cape & Northern Province & N West & W Cape & S Africa \\
\hline$E(1)$ & 20.93 & 16.13 & 9.47 & 22.91 & 29.45 & 21.69 & 36.87 & 22.66 & 6.75 & 19.33 \\
\hline$u$ & 48.55 & 29.96 & 28.21 & 39.11 & 32.91 & 28.53 & 46.04 & 37.95 & 17.87 & 33.89 \\
\hline c & 30.05 & 9.27 & 0.93 & 29.72 & 26.00 & 18.54 & 63.65 & 20.73 & 4.54 & 23.05 \\
\hline$W(1)$ & 41.02 & 0.89 & 0.11 & 24.65 & 5.73 & 3.23 & 11.35 & 1.84 & 0.58 & 12.54 \\
\hline $\mathrm{R}(1)$ & 22.03 & 5.60 & 2.59 & 11.49 & 8.98 & 4.40 & 17.58 & 7.20 & 2.12 & 9.70 \\
\hline$P(1)$ & 45.25 & 11.59 & 3.97 & 19.96 & 14.57 & 12.22 & 30.67 & 19.36 & 2.99 & 18.38 \\
\hline D & 52.75 & 36.83 & 25.07 & 43.96 & 34.19 & 19.10 & 37.29 & 29.65 & 17.85 & 34.81 \\
\hline L & 28.54 & 34.90 & 17.02 & 40.23 & 31.74 & 37.56 & 47.60 & 48.27 & 5.78 & 28.75 \\
\hline $\mathrm{H}$ & 45.07 & 14.09 & 2.56 & 36.51 & 31.07 & 18.54 & 64.96 & 29.54 & 8.83 & 27.88 \\
\hline $\mathrm{T}$ & 29.14 & 8.88 & 2.47 & 15.21 & 8.76 & 10.69 & 21.21 & 6.41 & 5.39 & 12.41 \\
\hline
\end{tabular}

$\mathrm{E}(1)$ : the proportion of adults over the age of 20 with no schooling (\%)

$\mathrm{U}$ : the unemployment rate $(\%)$

$\mathrm{C}$ : the proportion of households which use wood for cooking (\%)

$\mathrm{W}(1)$ : the proportion of households that gain access to water from a river, dam, spring or stream (\%)

$\mathrm{R}(1)$ : the proportion of households with no rubbish disposal (\%)

$P(1)$ : the proportion of households with no access to a telephone (\%)

D: the proportion of the population which is either living in informal dwellings, traditional dwellings, caravans, tents or homeless (\%)

L: the proportion of households that use candles for lighting (\%)

$\mathrm{H}$ : the proportion of households which use wood for heating $(\%)$

T: the proportion of households with no toilet (\%)

Source: Statistics South Africa, 1998.

(All unspecified or unstated categories have been excluded)

Table 2. The Anand-Sen Family of Measures for South Africa 1996.

\begin{tabular}{|c|c|c|c|c|c|c|c|c|c|c|}
\hline Measure & E Cape & Free State & Gauteng & KwaZulu Natal & Mpumalanga & N Cape & Northern Province & N West & W Cape & S Africa \\
\hline S(1)7 & 37.23 & 15.75 & 10.05 & 27.40 & 21.69 & 15.39 & 34.78 & 19.91 & 7.53 & 21.67 \\
\hline $\mathrm{S}(2) 7$ & 39.09 & 19.88 & 14.98 & 29.08 & 24.26 & 17.61 & 38.35 & 22.96 & 10.12 & 23.46 \\
\hline $\mathrm{S}(3) 7$ & 46.64 & 22.87 & 17.75 & 30.95 & 25.98 & 19.09 & 41.30 & 24.96 & 11.91 & 25.02 \\
\hline $\mathrm{S}(1) 5$ & 37.06 & 17.88 & 13.09 & 28.42 & 22.26 & 15.39 & 29.83 & 23.64 & 9.03 & 22.05 \\
\hline $\mathrm{S}(2) 5$ & 39.36 & 22.57 & 17.63 & 30.46 & 25.43 & 18.32 & 32.58 & 24.03 & 11.72 & 24.43 \\
\hline $\mathrm{S}(3) 5$ & 41.22 & 25.33 & 19.84 & 32.60 & 27.33 & 20.08 & 34.56 & 26.47 & 13.27 & 23.53 \\
\hline$S(1) 6$ & 34.64 & 12.23 & 7.55 & 24.64 & 19.61 & 14.77 & 34.36 & 18.28 & 5.81 & 19.48 \\
\hline$S(2) 6$ & 36.32 & 15.33 & 12.53 & 26.06 & 22.18 & 17.35 & 38.52 & 21.64 & 8.15 & 20.99 \\
\hline$S(3) 6$ & 37.76 & 17.77 & 15.74 & 27.34 & 23.98 & 19.09 & 41.90 & 23.98 & 10.08 & 22.40 \\
\hline$S(1) 7^{\prime}$ & 49.41 & 24.17 & 13.26 & 38.04 & 32.58 & 22.12 & 49.50 & 33.10 & 11.17 & 30.44 \\
\hline $\mathrm{S}(2) 7^{\prime}$ & 49.81 & 27.10 & 16.94 & 38.92 & 35.31 & 24.47 & 52.91 & 35.97 & 13.53 & 31.47 \\
\hline$s(3) 7^{\prime}$ & 50.24 & 28.95 & 19.10 & 39.79 & 37.67 & 26.60 & 56.08 & 38.63 & 15.05 & 32.82 \\
\hline
\end{tabular}

$\mathrm{S}(1) 7=$ the Anand-Sen measure for an alpha value of 1 and 7 indicators (\%) etc.

$\mathrm{S}(1) 7=$ the Anand-Sen measure for an alpha value of 1 and 7 indicators (\%) etc.
$\mathrm{S}(1) 5=$ the Anand-Sen measure for an alpha value of 1 and 5 indicators $(\%)$ etc.

$\mathrm{S}(1) 6=$ the Anand-Sen measure for an alpha value of 1 and 6 indicators $(\% \%)$ etc.

$\mathrm{S}(1) 7^{\prime}=$ the Anand-Sen measure for an alpha value of 1 and 7 indicators with 'soft' borderlines (\%) etc. 
It might be argued that the contrast between the human and expenditure poverty performances of KwaZulu Natal and the Free State may depend not so much on the dimensions selected but rather on the particular indicators chosen for each dimension. While there are no obvious alternatives for some of the indicators used (such as unemployment), in the case of two of the seven indicators used there are plausible alternatives which might be used. In the case of energy use, it might be argued that energy used for lighting and for heating are alternatives to energy used for cooking. In this context, the proportion of households that use candles for lighting and the proportion using wood for heating are listed in the 1996 Census publications. In the case of sanitation, it might be argued that the nature or absence of toilet facilities might be an alternative to an index relating to rubbish disposal. The proportion of households without any toilets is a plausible alternative to the proportion of the households without any rubbish disposal. These alternative indices are presented in Table 1. Clearly, KwaZulu Natal is doing worse than Free State in terms of all indices. Thus, using these indices will not affect the performance of the two states in terms of the Anand-Sen measures. It is also easy to check that the use of these indicators does not affect the position of the two states when one uses the Borda score.

What of the ranking of the remaining states? In all cases the worst three are: the Eastern Cape, Northern Province and KwaZulu Natal. Northern Province does worse than the Eastern Cape when enough importance is given to 'depth' and all seven indices are used. However, when the smaller list of indices is used, the Eastern Cape is worse than the Northern Province in terms of the family of Anand-Sen measures for the various chosen levels of $\alpha$. Nonetheless, the ranking might easily switch if more weight is given to education, since the Northern Province performs much worse than the Eastern Cape in terms of this dimension. As regards the states which are doing best, the Western Cape, Gauteng, the Northern Cape and the Free State are invariably, respectively, first, second, third and fourth best. The position of the Free State is much better than in most expenditure-based rankings, though it is not third best (as in Qizilbash, 2002). For many of the states in the 'middle' of the ranking-Mpumalanga, North West, Northern Cape and the Free State - the values of the Anand-Sen family of measures are relatively 'close', suggesting that relatively small changes in the weights attached to the different dimensions would change the orderings. So the rankings of these states are not particularly robust. It is easy to check this by assigning a considerably higher weight to one of the dimensions and comparing the resulting values of the indices for these provinces. As regards, the difference between using five and seven indicators, the comparison between Mpumalanga and North West hinges on this, with North West doing better when all seven indices are used.

How do these rankings compare with the Borda rankings based on the same indices? In Table 3 the rankings based on the Borda score are presented. Here the province which is doing worst (second worst, etc.) in terms of a particular index is given a rank order score of nine (eight, etc.). In the case of ties, if any two provinces are doing worse than three (four, etc.) provinces, they both get a rank order of four (five, etc.). The sum of the rank order scores is the Borda score, and the ranking based on it is the Borda ranking. In the Borda ranking the same method is used for ties. The Borda score and the Borda ranking using all seven indices as well as that based on just five indices are presented in Table 3. The ranking of the provinces is much the same as that based on the Anand-Sen family of measures. The only difference between the Borda rankings using seven indices rather than the subset of five indices is that the Free State and the Northern Cape 
Table 3. Rank Orders for Indicators, Borda Score and Borda Ranking for South Africa in 1996

\begin{tabular}{|c|c|c|c|c|c|c|c|c|c|}
\hline & & & & Province & & & & & \\
\hline & E Cape & Free State & Gauteng & KwaZulu Natal & Mpumalanga & N Cape & Northern Province & N West & W Cape \\
\hline$E(1)$ & 4 & 3 & 2 & 7 & 8 & 5 & 9 & 6 & 1 \\
\hline U & 9 & 4 & 2 & 7 & 5 & 3 & 8 & 6 & 1 \\
\hline C & 8 & 3 & 1 & 7 & 6 & 4 & 9 & 5 & 2 \\
\hline W(1) & 9 & 3 & 1 & 8 & 6 & 5 & 7 & 4 & 2 \\
\hline$R(1)$ & 9 & 4 & 2 & 7 & 6 & 3 & 8 & 5 & 1 \\
\hline$P(1)$ & 9 & 3 & 2 & 7 & 5 & 4 & 8 & 6 & 1 \\
\hline D & 9 & 6 & 3 & 8 & 5 & 2 & 7 & 4 & 1 \\
\hline Borda Score (7) & 57 & 26 & 13 & 51 & 41 & 26 & 56 & 36 & 10 \\
\hline Borda Rank (7) & 9 & 3 & 2 & 7 & 6 & 3 & 8 & 5 & 1 \\
\hline Borda Score (5) & 40 & 20 & 11 & 37 & 30 & 17 & 39 & 25 & 7 \\
\hline Borda Rank (5) & 9 & 4 & 2 & 7 & 6 & 3 & 8 & 5 & 1 \\
\hline Borda Score (6) & 48 & 20 & 10 & 43 & 36 & 24 & 49 & 32 & 9 \\
\hline Borda Rank (6) & 8 & 3 & 2 & 7 & 6 & 4 & 9 & 5 & 1 \\
\hline
\end{tabular}

Key:

$\mathrm{U}$ : the unemployment rate

$\mathrm{C}$ : the proportion of households which use wood for cooking

$\mathrm{W}(1)$ : the proportion of households that gain access to water from a river, dam, spring or stream

$R(1)$ : the proportion of households with no rubbish disposal

$P(1)$ : the proportion of households with no access to a telephone

$D$ : the proportion of the population living in informal dwellings, traditional dwellings, caravans, tents or homeless

Borda Score $(7)=E(1)+U+C+W(1)+R(1)+P(1)+D$

Borda Score $(5)=E(1)+U+W(1)+R(1)+D$

Borda Score $(6)=E(1)+U+C+W(1)+R(1)+P(1)$

Bordra Rank (7) according to Borda Score (7)

Borda Rank (5) according to Borda Score (5)

Borda Rank (6) according to Borda Score (6) 
are tied in 'third best' place if we use the full set of indices, while the Northern Cape beats the Free State to third best when one looks only at the subset of five indices. So the overall ranking of the states in terms of human poverty is fairly robust. In particular, KwaZulu Natal is third worst in terms of all the rankings just discussed. The contrast with Leibbrandt and Woolard's result that KwaZulu Natal has the third lowest level of (expenditure or income) poverty in terms of the Foster, Greer, Thorbecke class of measures is striking.

\section{Inter-provincial comparisons and the choice of 'bottom line'}

Thus far, I have set to one side any worries about robustness to how one defines the 'bottom line.' Vagueness or imprecision about this 'bottom line' has been the focus of the fuzzy set theoretic poverty literature, as well as of the literature on uncertainty about the 'true' poverty line, when data is 'noisy'. In related work, Qizilbash (2002) used an approach due to Cheli and Lemmi (1995) to define the boundaries of the zone of vagueness or 'fuzziness' in combination with data from the 1996 South African Census to rank the provinces of South Africa in terms of 'definite poverty'. The Cheli and Lemmi approach attempts to respond to worries about arbitrariness in the context of vertical vagueness - particularly those associated with a measure developed by Cerioli and Zani (1990) - by only treating the worst off category for each dimension in the sample as definitely poor, and treating the best off group in the sample as definitely not poor. If one were to use this methodology one would have to amend at least one of the cut-offs used in section 3: that relating to the shelter indicator. Indeed, only those who are in the worst-off category in this dimension-i.e. the homeless-would count as definitely poor in this dimension on the Cheli and Lemmi methodology. In related work, Clark and Qizilbash (2002) also argue, on the basis of a recent survey on 'The Essentials of Life', that a not insignificant proportion of people interviewed in three locations in South Africa thought that someone could get by with just about any sort of dwelling or access to water.' They conclude that if we are to define 'bottom lines' in terms of the views of ordinary South Africans, and to allow cut-offs as acceptable or 'admissible' if they are endorsed by a not insignificant proportion of South Africans, only those who have no access to water at all-even from a dam, stream, etc.- are definitely poor in the dimension of water access. Similarly, they conclude that only those with no dwelling - the homeless - are definitely poor in terms of shelter. In this case, their methodology echoes the Cheli and Lemmi methodology. The remaining cutoffs used in section 3 are consistent with both the Cheli and Lemmi methodology and the results reported by Clark and Qizilbash (2002).

If we follow these suggestions and 'toughen' the 'bottom lines' used in conjunction with the indices from the 1996 Census, then only a tiny proportion (either zero or very close to zero) are definitely poor in the dimensions of shelter and access to water. On this basis, we might exclude indices relating to these dimensions in ranking the provinces in terms of poverty. In the case of shelter, the only people who would count as poor would be the homeless. Since the percentage of the population that is homeless rounds to zero for each province, there is a case for excluding this variable in

9 Clark and Qizilbash (2002) use 'at least 5 per cent' as the crucial cut-off for a 'not insignificant' proportion of the sample they are concerned with. 
comparisons between the provinces. As regards water, however, only defining those who have no access to water as poor, involves effectively saying that anyone with any access to water is non-poor in this dimension in the present context. This is not implied in Clark and Qizilbash's work because they allow for vagueness about the borderline between the poor and the non-poor. In the context of this paper, it seems implausible to treat those with any access to water as non-poor in this dimension. So I stick to the original cut-off used in this case. The effect of 'toughening' the borderlines is thus only to remove the shelter variable.

The values for the Anand-Sen family of measures for the remaining six indices is given in Table 2. The Borda scores and ranking based on these six indices is given in Table 3. While the ranking based on the Anand-Sen family of measures is not very different, it is noticeable that Northern Province has again taken over from the Eastern Cape as the worst off province. KwaZulu Natal remains third worst, and is consistently worse than the Free State. The Free State does better than the Northern Cape in terms of all the Anand-Sen measures, while Mpumalanga and the North West are equally bad if enough weight is given to 'depth' (with Mpumaplanga doing worse otherwise). The result about the relative positions of the Northern Province, the Eastern Cape and KwaZulu Natal also emerges in the Borda ranking which only looks at the six indicators. In the Borda ranking, the Free State is third best (echoing the result in Qizilbash, 2002).

It is also worth noting some implications of 'softening' the bottom lines used. So, in Table 4, headcount indices relating to all seven dimensions are included. In a number of cases, the 'cut-off' has been set less stringently than before. In the case of education those who have begun, but not completed, primary education are included. In the case of energy used for cooking, all those who use dung for cooking are now included. In the case of water, those with access from a well or borehole are also included. In the case of access to a telephone, those who only have access to a phone at some distance from home are now included. In the case of rubbish disposal, those who have their own refuse dump are included. In the remaining two cases (shelter and employment), the cutoffs used in section 3 are adopted.

Values of the Anand-Sen family of measures with $\alpha=1,2$ and 3 for these indicators are presented in Table 2. It is noticeable that the Northern Province is worse than the Eastern Cape for all choices of $\alpha$. Similarly, the Free State is doing worse than the Northern Cape. Since the values of the Anand-Sen family of measures are relatively 'close' for all values of $\alpha$ in both comparisons the use of different weights for specific dimensions might reverse the results. The positions of the various states is, nonetheless, not affected by the weight given to 'depth'. Finally, as in all the previous rankings KwaZulu Natal is third worst. The Borda ranking based on these indicators is shown in Table 5. In the Borda ranking the Free State is fourth best. However, the Eastern Cape is now doing worse than Northern Province, while North West is doing worse than Mpumalanga. Otherwise, the ranking is much the same as that based on the Anand-Sen family of measures. In particular, KwaZulu Natal remains third worst. 
Table 4. Headcount Poverty Indices Using 'Soft Borderlines' in Various Dimensions in South Africa 1996

\begin{tabular}{|c|c|c|c|c|c|c|c|c|c|c|}
\hline Indicator & E Cape & Free State & Gauteng & KwaZulu Natal & Mpumalanga & N Cape & Northern Province & N West & W Cape & S Africa \\
\hline$\overline{E(2)}$ & 42.46 & 38.55 & 21.15 & 40.80 & 44.61 & 42.68 & 48.92 & 43.14 & 22.40 & 36.03 \\
\hline U & 48.55 & 29.96 & 28.21 & 39.11 & 32.91 & 28.53 & 46.04 & 37.95 & 17.97 & 33.89 \\
\hline$C(2)$ & 43.44 & 10.82 & 0.94 & 30.36 & 26.47 & 18.60 & 64.17 & 21.59 & 4.54 & 24.22 \\
\hline $\mathrm{W}(2)$ & 44.89 & 4.21 & 1.79 & 31.43 & 12.40 & 7.30 & 21.29 & 12.94 & 1.42 & 17.50 \\
\hline $\mathrm{R}(2)$ & 62.12 & 30.49 & 9.97 & 52.91 & 56.47 & 24.10 & 84.73 & 59.33 & 9.91 & 42.35 \\
\hline$P(2)$ & 51.63 & 18.34 & 5.71 & 27.72 & 20.98 & 14.52 & 44.08 & 27.26 & 4.13 & 24.27 \\
\hline D & 52.75 & 36.83 & 25.07 & 43.96 & 34.19 & 19.10 & 37.29 & 29.29 & 17.85 & 34.81 \\
\hline
\end{tabular}

$E(2)$ : the proportion of adults over the age of 20 with either schooling or that have not completed primary education (\%)

$\mathrm{U}$ : the unemployment rate (\%)

$\mathrm{C}(2)$ : the proportion of households which use wood or dung for cooking (\%)

$\mathrm{W}(2)$ : the proportion of households that gain access to water from a river, dam, spring, stream, well or borehole (\%)

$R(2)$ : the proportion of households with no rubbish disposal or own rubbish dump (\%)

$\mathrm{P}(2)$ : the proportion of households with either no access to a telephone or access to a telephone at some distance (\%)

D: the proportion of the population living in informal dwellings, traditional dwellings, caravans, tents or homeless (\%)

Source: Statistics South Africa, 1998.

(All unspecified or unstated categories have been excluded)

Table 5. Rank Orders for Indicators, Borda Score and Borda Ranking Using 'Soft Borderlines' for South Africa in 1996

Province

\begin{tabular}{|c|c|c|c|c|c|c|c|c|c|}
\hline & E Cape & Free State & Gauteng & KwaZulu Natal & Mpumalanga & N Cape & Northern Province & N West & W Cape \\
\hline$E(2)$ & 5 & 3 & 1 & 4 & 8 & 5 & 9 & 7 & 2 \\
\hline U & 9 & 4 & 2 & 7 & 5 & 3 & 8 & 6 & 1 \\
\hline$C(2)$ & 8 & 3 & 1 & 7 & 6 & 4 & 9 & 5 & 2 \\
\hline $\mathrm{W}(2)$ & 9 & 3 & 2 & 8 & 5 & 4 & 7 & 6 & 1 \\
\hline $\mathrm{R}(2)$ & 8 & 4 & 2 & 5 & 6 & 3 & 9 & 7 & 1 \\
\hline $\mathrm{P}(2)$ & 9 & 4 & 2 & 7 & 5 & 3 & 8 & 6 & 1 \\
\hline D & 9 & 6 & 3 & 8 & 5 & 2 & 7 & 4 & 1 \\
\hline Borda Score & 57 & 27 & 13 & 46 & 40 & 26 & 57 & 41 & 9 \\
\hline Borda Rank & 9 & 4 & 2 & 7 & 5 & 3 & 8 & 6 & 1 \\
\hline
\end{tabular}

$E(1)$ : the proportion of adults over the age of 20 with either no schooling or with some but not complete primary education

$\mathrm{U}$ : the unemployment rate

$C(2)$ : the proportion of households which use wood or dung for cooking

$\mathrm{W}(2)$ : the proportion of households that gain access to water from a river, dam, spring, stream, well or borehole

$\mathrm{R}(2)$ : the proportion of households with no rubbish disposal or own rubbish dump

$\mathrm{P}(2)$ : the proportion of households with either no access telephone or access to a telephone at some distance

$D$ : the proportion of the population living in informal dwellings, traditional dwellings, caravans, tents or homeless

Borda Score $=E(2)+U+C(2)+W(2)+R(2)+P(2)+D$

Borda Rank=Rank According to the Borda Score 


\section{Policy relevance}

These results are highly relevant to proposals relating to the allocation of poverty eradication funds to the provinces on the basis of poverty incidence. In recent work, Hirschowitz et al. (2000) have argued for the use of two Statistics South Africa (SSA) indices - the household circumstances index and the household infrastructure index-in this context. The SSA proposal is an attempt to alter the basis of the policy for distributing funds which focusses simply on household expenditures. Both SSA measures are multi-dimensional. The existing rationale for distribution clearly favours those provinces which tend to do badly in terms of expenditure poverty as opposed to human poverty. Indeed, as Qizilbash (2002) argues, the Free State would do considerably better on the basis of a policy which focusses on expenditure poverty than on one which focusses on a Borda ranking using a multiplicity of dimensions and direct deprivation measures. Similarly, KwaZulu Natal would do considerably better on the basis of a policy which focusses on some multi-dimensional human poverty measures, than it would if the policy was based on expenditure headcount indices.

The various measures used in this paper-such as the Anand-Sen family of measures for various levels of $\alpha$ and the Borda score - could be used to do much the same work that the SSA indices are meant to do. However, when the ranking of states is dependent on the choice of specific dimensions, cut-offs, or weights, there is likely to be controversy about the use of any specific formula which is used for the distribution of funds. In such cases, the particular decision which any government makes must be justified in some way. The discussion of robustness above may actually prove useful in this context.

The ranking of provinces in terms of the household circumstances and household infrastructure indices involve a number of stages (set out in Hirschowitz et al. 2000: 7480 ). In the first stage, a set of indicators is chosen (for household infrastructure and other concerns, respectively) on the basis of a principal-component analysis. The aim here is to include indices which are 'informative' and which are not closely correlated. In the second stage, the performance of provinces in terms of the chosen indices is judged using a rank order method of a particular sort for levels of deprivation. Specifically, performance in terms of each indicator is classified into various rank order scores - with three being assigned to the province with a relatively large proportion of the population living in the worst conditions, and one to a province with most of its population living in the best conditions, while provinces which fall in between are given a score of two. The numbers which emerge from this exercise are then added up to give the 'interim score' for each province. The interim scores are then divided by the number of indices used to give an average interim score, and the average is then multiplied by the square root of population to give the relevant indices (SSA, 2000: 76-7). The method is clearly a combination of rank order scoring and an average using equal weights. It involves very specific cuts-offs and weights which are not justified. Any distribution of funds based on it might be highly controversial for this reason.

It is clear that much the same sort of exercise could be carried out using the Borda score or one of the Anand-Sen family of indices. However, as with the SSA measures some justification for the weighting, the choice of indicators and cut-offs used would need to be given. Equal weights can be justified in a limited way, on the grounds that there is no 
good reason to deviate from equal weights. However, they can also be justified, on the basis of the results in Clark and Qizilbash (2002) which suggest that most of the central dimensions of poverty are given roughly equal weight on average in questionnaire responses from three locations in South Africa. Such questionnaire responses on a larger sample of South African households might certainly help to justify choices relating to weights, even though an average of marks can hide a wide disparity of responses.

In cases where the ranking is not robust to changes in the specific indices and cut-offs used, further justification is required. Where the ranking is 'close' on virtually all alternative measures, it may be perfectly sensible to give the relevant provinces the same level of funding per household. This might be the case, for example, with the Free State and the Northern Cape. It might also be the case as regards the relative positions of Mpumalanga and North West. Alternatively, one might suppose that in such cases the larger share of funds per household might be allocated to the province with the most 'definite poverty'. This could be the province which has the highest level of poverty using the narrowest range of dimensions or the one with the highest level of poverty when the 'toughest' cut-offs are used. In the first case, the policy would favour the Eastern Cape, while in the latter it would favour the Northern Province. However, it is not obvious whether a 'tough stance' ought to favour restricting the dimensions used, or tightening the borderlines for particular indices or both. Being 'tough' about both the selected dimensions and the borderlines used may lead to a more determinate conclusion as regards policy, if policy makers wish to take a 'tough stance'.

As regards the better end of the poverty rankings, clearly the Western Cape is best, and Gauteng second best in terms of all ranking methods employed and ought to have the smallest allocations per household. ${ }^{10}$ At the bottom end of the ranking, KwaZulu Natal is in the third worst position on all variations on the multi-dimensional measures presented here, and should have the third highest allocation per household. Finally, as regards the Eastern Cape and the Northern Province the ranking is not robust. One response to this would be to give both provinces the same funding per household. This would alter the ranking according to the 'interim scores' which are used in the construction of the household circumstances and household infrastructure indices for 1996, as presented by SSA (2000: 778-8). According to the score used for infrastructure, the Eastern Cape is doing worse than the Northern Province, while the score used in the household circumstances index is the same for the two provinces. Consequently joint use of the two indices would favour the Eastern Cape.

It is not obvious from looking at the rankings themselves why the remarkably robust result about KwaZulu Natal and the Free State emerges. One might conjecture that public services in the Free State are superior to those in KwaZulu Natal. It is for this reason, it might be argued, that a high level of human poverty can persist in the KwaZulu Natal even when income poverty is relatively low. The policy implication would be that public services need to be improved in KwaZulu Natal. However, this policy implication is based on a conjecture which needs to be assessed. Furthermore, while poverty alleviation funds might be allocated on the basis of multi-dimensional human poverty rankings rather than expenditure rankings, the multi-dimensional picture of poverty obviously also yields other important insights - such as particularly sharp

10 Clearly, this argument only applies at the aggregate level and may need to be adjusted to allow for variations in the levels of poverty within provinces. 
shortfalls in particular dimensions - which must inform policy. Clearly, it is not just the rankings, as such, which are relevant to policy. The overall performance in terms of the Anand-Sen family of measures over time can, for example, be used to evaluate the success or failure of poverty-eradication policy. So while this paper has been primarily concerned with the issue of rankings, a multi-dimensional approach can yield many policy relevant insights which a focus on multi-dimensional rankings alone might obscure.

\section{Conclusions}

There are several distinct issues which relate to arbitrariness and robustness involved in measures and rankings involving a multi-dimensional poverty framework. In this paper, the focus has not been on identification problems. It has been on certain measures and inter-provincial rankings based on existing dimension specific data for South Africa in 1996. It turns out that the inter-provincial poverty rankings based on the Anand-Sen family of measures and the Borda score are fairly robust. The results confirm claims in the related literature about the relative position of the Free State and KwaZulu Natal in inter-provincial rankings even when issues relating to the choice of dimensions and the selection of 'bottom lines' as well as various weighting issues are allowed for. Even when the rankings are not robust, furthermore, the discussion suggests ways in which various allocations might be justified.

\section{References}

Anand, S. and Sen, A. K. (2000). The Income Component of the Human Development Index. Journal of Human Development 1: 83-106.

Atkinson, A. B. (1987). On the Measurement of Poverty. Econometrica 55: 749-64.

Atkinson, A. B. (2003). Multidimensional Deprivation: Contrasting Social Welfare and Counting Approaches. Journal of Economic Inequality 1(1): 51-65.

Atkinson, A. B. and Bourguignon, F. (1987). The Comparison of Multidimensional Distributions of Economic Status. Review of Economic Studies 49: 183-201.

Bourguignon, F. and Ckakravarty, S. R. (2002). Multi-dimensional Poverty Orderings. Working Paper No. 2002-22. DELTA: Paris.

Bourguignon, F. and Chakravarty, S. R. (2003). The Measurement of Multidimensional Poverty. Journal of Economic Inequality 1(1): 25-49.

Brandolini, A. and d'Alessio, G. (2001). Measuring Poverty in the Functioning Space. Paper Presented at the conference on 'Justice and Poverty: Examining Sen's Capability Approach' St Edmund's College, Cambridge, June.

Cerioli, A. and Zani, S. (1990). A Fuzzy Approach to the Measurement of Poverty. In C. Dagum and M. Zenga (eds) Income and Wealth Distribution, Inequality and Poverty, Berlin: Springer Verlag, 272-84.

Cheli, B. and Lemmi, A. (1995). A 'Totally' Fuzzy and Relative Approach to the Measurement of Poverty. Economic Notes 24(1): 115-134. 
Chiappero Martinetti, E. (1994). A New Approach to the Evaluation of Well-being and Poverty by Fuzzy Set Theory, Giornale Degli Economisti e Annali di Economia 53: 367-88.

Chiappero Martinetti, E. (1996). Standard of Living Evaluation Based on Sen's Approach: Some Methodological Suggestions. Notizie di Politeia 12(43-4): 37-53.

Chiappero Martinetti, E. (2000). A Multi-Dimensional Assessment of Well-being Based on Sen's Functioning Theory. Rivista Internationale di Scienzie Sociali CVIII: 20731 .

Clark, D. A. and Qizilbash, M. (2002). Core Poverty and Extreme Vulnerability in South Africa. Economics Research Centre, Discussion Paper 2002-3. University of East Anglia.

Clark, D. A. (2002). Visions of Development. Cheltenham: Edward Elgar.

Dasgupta, P. (1993). An Inquiry into Well-Being and Destitution. Oxford University Press, Oxford.

Dutta, I., Pattanaik, P. and Xu, Y. (2003). On Measurement of Deprivation and the Standard of Living in a Multi-Dimensional Framework on the Basis of Aggregate Data. Economica 70: 197-221.

Foster, J. and Shorrocks, A. F. (1988). Poverty Orderings and Welfare Dominance. Social Choice and Welfare 5: 91-110.

Haq, M. (1995). Reflections on Human Development. Oxford: Oxford University Press.

Hirschowitz, R. et al. (2000). Key Baseline Statistics for Poverty Measurement. In Measuring Poverty in South Africa. Statistics South Africa. Statistics South Africa, Pretoria, 53-81.

Klasen, S. (1997). Poverty, Inequality and Deprivation in South Africa: an Analysis of the 1993 SALDRU Survey. Social Indicators Research 41: 51-94.

Klasen, S. (2000). Measuring Poverty and Deprivation in South Africa. Review of Income and Wealth 46(1): 33-58.

Leibbrandt, M. and Woolard, I. (1999). A Comparison of Poverty in South Africa's Nine Provinces. Development Southern Africa 16(1): 37-54.

Lelli, S. (2001). Factor Analysis vs. Fuzzy Sets Theory: Assessing the Influence of Different Techniques on Sen's Functioning Approach. Paper Presented at the conference on 'Justice and Poverty: Examining Sen's Capability Approach' St Edmund's College, Cambridge, June.

Maasoumi, E. (1986). The Measurement and Decomposition of Multidimensional Inequality. Econometrica 54(4): 991-7.

Majumdar, M, and Subramanian, S. (2001). Capability Failure and Group Disparities: Some Evidence from Indian for the 1980s. Journal of Development Studies 37(5): 104-140.

May, J. (ed) (2000). Poverty and Inequality in South Africa: Meeting the Challenge. Zed Books: New York and London. 
Ngwane, A. et al. (2001). Poverty in South Africa-A Statistical Analysis. Development Southern Africa 18(2): 201-13.

Qizilbash, M. (1997). Pluralism and Well-Being Indices. World Development 25(12): 2009-26.

Qizilbash, M. (2002). A Note on the Measurement of Poverty and Vulnerability in the South African Context. Journal of International Development 14: 757-72.

Qizilbash, M. (2003). Vague Language and Precise Measurement: the Case of Poverty. Journal of Economic Methodology 10(1): 41-58.

Ravallion, M. (1994). Poverty Rankings Using Noisy Data on Living Standards. Economics Letters. 45: 481-5.

Sen, A. (1992). Inequality Reexamined Clarendon Press, Oxford.

Sen, A. (1993). Capability and Well-being. In The Quality of Life, M. Nussbaum and A. Sen (eds) Clarendon Press, Oxford, 30-55.

Sen, A. (1999). Development as Freedom. Oxford University Press, Oxford.

Statistics South Africa. (1998). Census in Brief. Statistics South Africa, Pretoria.

Statistics South Africa. (2000). Measuring Poverty in South Africa. Statistics South Africa, Pretoria.

Tsui, K. Y. (1997). Multidimensional Poverty Indices. Social Choice and Welfare 19: 69-93.

United Nations Development Programme (1997). Human Development Report 1997. Oxford University Press, Oxford and New York. 